\section{Las derechas y la condición civil de las mujeres en el Cono Sur (1945-1990)}

Verónica Giordano
Verónica Giordano es Profesora de la Facultad de Ciencias Sociales, Universidad de Buenos Aires, e Investigadora Asistente del CONICET, con sede en el Instituto de Investigaciones Gino Germani de esa Facultad.

Marcelo T. de Alvear 2230, C 1122 AAJ, Ciudad Autónoma de Buenos Aires, Argentina.

e-mail: veronicagiordano@fibertel.com.ar

\section{Resumen}

El artículo propone un análisis comparativo del peso histórico de las derechas en el proceso de ampliación de los derechos civiles de las mujeres en Argentina, Brasil, Chile y Uruguay en el período 1945-1990. En los cuatro países, gobiernos democráticos, con influencia variable de las derechas (Uruguay y Brasil), y significativamente, gobiernos de las dictaduras institucionales de las Fuerzas Armadas, conducidos por grupos de las derechas (Argentina y Chile), llevaron adelante una importante reforma del estatuto jurídico civil de las mujeres. En efecto, en distintos momentos, los respectivos gobiernos legislaron sobre un componente primordial de los derechos civiles: la "capacidad plena». Con matices, fuera que se tratase de situaciones de democracia 0 de dictadura, en todos los casos, la inclusión de las mujeres en el estatuto de persona jurídica plenamente capaz fue limitada por fuerzas de las derechas.
El artículo presenta resultados parciales de una investigación que es parte de un proyecto colectivo en curso, Proyecto S 057 Condiciones sociohistóricas de la democracia y la dictadura en América Latina, 1954-2010, Programación Científica 2008-2010 de la Secretaría de Ciencia y Técnica de la Universidad de Buenos Aires (UBACyT). Asimismo, retoma, reformula y amplía planteos inicialmente expuestos en las XI Jornadas Interescuelas / Departamentos de Historia (Tucumán, septiembre de 2007), bajo el título "Las derechas y la condición civil femenina (1930-1980). Argentina, Brasil, Chile y Uruguay en perspectiva comparativa».

\section{Summary}

This article offers a comparative analysis of the historical influence of the rights in the building of women's civil statute in Argentina, Brazil, Chile and Uruguay during the period 1945-1990. In the four countries, democratic governments with variable influence of the rights (Uruguay and Brazil) and, significantly, military institutional dictatorships headed by right-wing groups (Argentina and Chile) carried out an important reform of women's civil juridical statute. In fact, at different times, such governments legislated on a primary element of civil rights: the "full capacity". In different ways, under a democratic regime or under a dictatorship, in all countries, the inclusion of women in the statute of civil person with full capacity was restricted by right wing forces. 


\section{EL PLANTEO DEL PROBLEMA}

Salvo algunas contribuciones recientes, los estudios historiográficos y de ciencias sociales que abordaron el rol de las derechas en los conflictos políticos y las luchas por el poder en el Cono Sur han enfatizado su carácter reaccionario, especialmente en determinadas coyunturas históricas, más precisamente, las de los años veinte y treinta. Esto último ha colaborado, aunque fuera involuntariamente, con una fijación de sentido que atribuyó a esa categoría política cierta inmutabilidad ${ }^{1}$.

Por otra parte, la inclusión de las mujeres en la esfera civil de la ciudadanía es un aspecto que, en general, ha sido inadvertido por los estudios especializados. Los análisis de género han mirado con más detenimiento el desarrollo histórico de los derechos políticos y de los derechos sociales en el curso de la construcción de la ciudadanía pretendidamente acumulativa y universal ${ }^{2}$.

Este artículo propone hacer una contribución en los dos sentidos arriba señalados a partir de un análisis comparativo del peso histórico de las denominadas derechas en el proceso de ampliación de los derechos civiles de las mujeres en Argentina, Brasil, Chile y Uruguay en el período 1945-1990. En los cuatro países hubo una importante reforma del estatuto jurídico civil de las mujeres. En distintos momentos, los respectivos gobiernos legislaron sobre un componente primordial de los derechos civiles: la «capacidad plena». No obstante, el proceso tuvo características particulares según se trató de gobiernos democráticos, en los cuales la influencia de las derechas fue variable (Uruguay y Brasil), o de gobiernos no democráticos -más precisamente, dictaduras institucionales de las Fuerzas Armadas-, en los cuales el proceso estuvo conducido por grupos de las derechas (Argentina y Chile).

Se sostiene una denominación en plural, esto es, «las derechas», tal como propone Sandra Mc Gee Deutsch en su estudio sobre la actuación de estos grupos en Argentina, Brasil y Chile entre fines del siglo XIX y finales de los años $1930^{3}$.

\footnotetext{
1 Un trabajo de referencia obligada en los estudios sobre las derechas en América Latina, y que permite discutir la fijación de sentido señalada arriba, es el de: Sandra McGee Deutsch (2005). Este trabajo también interesa aquí por su reflexión en relación con la dimensión de género.

2 Entre los estudios que se ocupan de los derechos civiles en el análisis de la ciudadanía y derechos de las mujeres puede consultarse: Barrancos (2007) y Lavrin (1995). Sobre las asincronías entre derechos civiles, políticos y sociales con atención a la cuestión de género, puede consultarse Lobato (1997). Mi propia tesis de doctorado discute los derechos civiles de las mujeres (Giordano, 2007).

${ }^{3}$ Advirtiendo el carácter no monolítico y circunstancial del concepto, Deutsch opta por la denominación en plural y ofrece una definición «deliberadamente breve»: «la derecha se consolida en reacción a las tendencias políticas igualitarias y liberadoras del momento -cualesquiera que sean éstas- y a otros factores que a su juicio socavan el orden social y económico. Teme que los impulsos niveladores y los ideales revolucionarios
} 